that non-obstructive vesical retention does exist, although explanation of the cause of this trouble thus far given is not to my mind convincing. The mystery surrounding the condition in some of the cases, I venture to suspect, might be cleared up, were it possible to have a more exact knowledge of the functional mechanism of the vesicoprostatic outlet than it is possible to acquire by cystoscopic observation. A slight, valvular abnormality might be found to account for the condition in some instances, while a proportion of the other cases may belong to the category of diseases of the central nervous system, notwithstanding the lack of signs to support such diagnosis.

Those cases that are unmistakably outside of either of these divisions are not yet fully explained.

\section{TECIINIC OF TREATMENT}

For the treatment of that class of cases which is spoken of as mechanical, surgical measures are the only means that can be expected to afford relief. I still cling to the technic to which it has been my wont to resort from time to time, the end-results of which give weight to the force of its claims. It is now twelve years since the first operation was performed and the reasons advanced in favor of this special method then are still held to at present; on account of improvement in technic they have become all the stronger and may be appreciated by the following brief descripition:

Local, instead of general, anesthesia may be employed. A small perineal ent is made, which brings the operator close to the site of trouble and allows the introduction of the index-finger to investigate the condition at the neck of the bladder and the degree of existing contraction. The galvanocautery knife is then introduced and, under electrical cauterization, the vesical constriction is excised, on one or both sides, to such an extent as may be deemed advisable; this is accomplished without hemorrhage during or after the operation. The finger may be then reintroluced to ascertain the completeness of the incision or defect thereof; in the latter instance, it may be supplemented by another or longer incision. Finally, rest of the bladder, avoidance of straining, insured by the absence of the necessity to urinate aiter the operation, the short period of confinement and radical removal of the cause, are all advantages to be counted. By way of comparison, it has been my experience to come in con"tact in the hospital with a number of patients who have been operated on intravesically without the establishment of perineal drainage. 'The great distress and complicated condition that ensued in these cases, necessitating the emergent operation of immediate suprapubic drainage to relieve the bladder of distention and infected bloodclots, have further strengthened my conviction in favor of this operative technic.

25 Park Avenue.

Pain and Cancer.-The eurliest and often for a long time the only symptom of intrinsic laryngeal eancer is loarseness or some well-murkel alteration of the ordinary voice. I implore you to rid your minds of the idea that "pain in the throat," or "pain shooting toward the ear," or "pain or dif. ficulty in swallowing" are signs of early cancer. One wishes that no mention of them was made in surgical text-hooks, for they are Jate symptoms, so terribly late that when they make their appearance the patient's chance of cure las probably gone, for the disease has then become extrinsic as well as intringie, secondary deposits have probably taken place in the glands of the neck, and life can only be saved or prolonged by the mutilating operation of laryngectomy.--Herbert Tilley in Clin Jour.

\section{PROS'L'TOTOMY BY THE METHOD OF GOLDSCHMID'T *}

CHARJES M. HARPSTER, M.D.

Genito-Urinary Surgeon, Toledo City IIospital

'TOJLDO, 01110

A large prostate may cause little trouble, while a small gland may cause complete and continuous retention. Contraction of the bladder neck at times causes annoying conditions and is often overlooked by practitioners, who advise against any operative procedure because a large gland is not found on examination by rectum. In cases of contraction of the blaclder neck, without enlargement of the gland, it is of no avail to remove the prostate. A slit of the median bar, when present, through the urethra, is simple, and, in cases in which drainage is not essential, is to my mind best accomplished by the method under discussion.

I shall relate briefly some of my experiences with the Goldsclumidt instruments.

One patient, a man aged 67 , had had a perineal prostutectomy performed and was unable to void urine without the use of a catheter. At the Toledo Hospital I incised the obstructing band with the Goldschmidt cautery, and the patient was able to void at once, and has been able to void over a period of about eighteen months.

Another patient had had a portion of the utricle removed by a perincal operation. He suffered from constant burning in the deep methra and pain on urination. At times considerable pus was passed by vrethra, and also some blood; this condition continued for several years. On examination with the Goldschmidt vrethroscope, about twelve months ago, I found a large soft mass growing from the utricle. This mass I removed with the cautery knife; relief was rapid and has been permanent up to this time.

Another patient, aged 74 , who was operated on at the I'oledo Hospital, had suffered from retention at times. The prostate was somewhat enlarged, and a distinct and firm band, with contraction of the bladder neck, was found. An incision was made with good jesults.

In a number of cases of beginning enlargement with lirinary disturbances incisions have been made with much improvement of the condition.

I have treated a number of cases of median obstruction and two cases of papillomas of the decp urethra in a similar manner.

Not to go into greater detail, in the cases which I have selected for this procedure the results have been uniformly good. In one case a violent urethral chill came on after instrumentation, and I have been. unable to complete this operation, as the patient refuses further treatment. Goldschmidt has used the procedure repeatedly on the same patient and numerous incisions have been made at different times. The delicate construction of the instrument is one of the most serious drawbacks, fis the cautery and light are easily burned out; also occasionally bleeding occurs and obscures the field of vision, although if considerable care is used and strong pressure of the irrigating fluid secured this can be avoided. I have never seen any alarming hemorrhage take place from its use. I watched carefully the work of Goldschmidt, Wossidlo and others for a number of montls and in their experience bleeding dnes not occur often. A large residum can be reduced several hun-

* Read in the Symposinm on Obstacles to Evacuation of the Bladder in the Section on Genito-trinary Discases of the Amerien Medical Association, at the Slxiy-'Third Annual Session, beld at Atluntle City, Junc, 1912. 
dred cubic centimeters after the first cauterization, as in rule.

'The statements oftenest made by those opposed to the method, that it is unsurgical and that the repeated cauterizations leave the prostatic portion scarred and

- Luttered, are not true of the procedure in the hands of careful operators. If used in all cases of prostatic obstruction the method, on the whole, is bound to be a failure. The contention that in those cases in which cauterization has been performed prostatectomy afterward becomes a necessity, because of infection and jeplacement of the cauterized tissue by new growth or the obliteration of the new channel by the enlargement jtself, is well founded, if this operation is used in cases which are not adapted to it.

In a recent article Dr. Young says :

During recent years I liave appreciated more and more that there existed a group of prostatic obstructions which could not he very sutisfactorily tested by either perineul or suprapubio prostutectomy; the cuses of intlammutory mediun bar formufion or contracture of the neck of the bladder.

I have developed an entire new procelure-the uretliroscopic median bar excision by means of a special "punch"-which I lat ve used since April 20,1911 , on about seventy patients with 110 deaths and with excellent results. This method makes it possible to perfect the result obtained either by perinenl or by suprapubic prostatectomy in enses in which, by the contracture of the tissues after operation, slight obstruction is jroduced.

The instrument of Buerger is valuable for examination, and I wish it were possible to have the cautery feature attached.

A great instrument was brought into use when Nitze perfected his cystoscope. Obstacles which had seemed unconquerable surrendered, one by one, to his energetic and persevering will until a result was attained which $i s$ so simple that the original problem appears to have been an easy one. Without relying on the achievements of others, Nitze worked independently and set up in place of unsafe and uncertain methods which could be carried out only by master's in our profession, an easy, positive and definite method of examination which has jroved a blessing to sufferers. At first the use of the Nitze instrument was intended only for the connecting urinary organs, but it was soon applied to the examination of the bladder and uretors.

\section{ADVANCE IN ENDOSCOPIC METIIODS}

Endoscopy of the stomach, according to the method of Nitze, was Inter taken up by von Mikulicz, who also developed the exploration of the urethra with an instrument which made it possible to throw light into this canal. Oberlaender likewise advanced and improved this method, but in spite of his efforts he was unsuccessful in reaching a result which can be compared with that of illuminating the bladder. Goldschmidt says: "We are now able to know the exact normal or pathologic conditions of the bladder, and the same can be obtainable for the urethra."

The old endoscopic experiments on the bladder and methra by Desormeaux, which were carried on still furtier by Grünfeld, consisted in nothing more than the insertion of the largest possible tube; over the inserted end of this tube, one portion of the mucous membrane of the bladder after another was viewed is the tube was vithdrawn, by the reflection of light through the tube from the outside. At the best, only such portions of the wall of either the bluditer or: the urethra could be viewed at one time as could be surfaced over the end of this small tube. 'This condition of affairs was changed, as far as examination of the bladder was concerned, when Nitze invented and applied a finely developed Jenssystem, by the aid of which he could view a portion of the bladder many times larger than the inserted end of the instrument. Not all improvements in the last ten years were essential to the principles of the shape of the instruments, but have been usually applied to the electric technicalities of the lighting features of the cifferent cystoscopes and urethroscopes. Excellent photograplis of the interior of the bladder and urethra, attesting to the diligence and ingeniuity of the photographer, liolman, have been made by the use of different appliances.

Goldschmidt started his experiments some years ago along the line of Nitze's lens-system, and by liard work and close observation to detail he was able to solve the problem. By the use of cystoscopic optic and convex Ienses of smaller diameter than the object to be seen he produces a wide field of vision. When such collective linses are inserted into a lighted tube, the rays coming from the inner surface and end of the tube will be guthered by the lenses, affording a view of the interior, it the end of the optic. 'This picture can be enlarged through a convenient ocular, just as is done with pictures of relative objects in endoscopy.

Many trials were necessary before Goldschmidt was able to construct a practicable and simple instrument. In the progress of his work Goldschmidt used only living subjects and constantly adhered to practical methods. Ile used water as a dilating medium, instead of air or any of the varions gases. While trying to produce the largest possible expansion by strong pressure of the (lilating medium, he found, much to his astonishment, that only a little dilatation was necessary to produce a uniform tube of the urethra which could be accurately viewed with his optical appliances.

It would seem that such a procedure would be difficult for the anterior as well as the posterior urethra, when it is considered that they are separated from each other by a strong muscular compressor. Goldschmidt, howcver, hus been led by numerous trials, under different and various circumstances, to a method whereby he can low with a simple instrument view the posterior urethra, copecially the verumontanum and prostate, with great cjearness.

Urination depends on the normal formation and normal condition of the prostatic urethra, bladder, etc., which are frequently impaired or changed by pathologic conditions of the prostate gland. An extraordinarily complicated system of tissues is located in the prostatic mrethra. - Infiltrations from old strictural processes, shallow ulcerations, diverticular changes, etc., can be readily scen.

The orifices of the ejaculatory ducts, pathologic forms of the colliculus seminalis, changes in the posterior urethra, changes in the prostatic labia, irregular passages to the bladder, a complete picture of the prostatic urethra, and, finally, a picture that shows the action of the sphincters brought out by the intravesical passage of the urine, can be seen.

\section{TIIE GOLDSCHMID'T INSTIUMEN'I AND ITS USE}

The instrument is so constructed that a stream of water can flow through the space between the endoscope and optic into the urethra and douche it out. The instrument ends vesically with either a rounded point cl a bill-shaped point, and is inserted with a well-fitting obturator into the urethra, permitting cold or hot boric acid solution to run from an irrigator into the water- 
chamber. 'To dourehe ont the anterior urethra only a slight pressure is necessary, but to clonche out the posterior urethra it is necessary to raise the jrrigator to abont 2 meters above the pelvis of the patient. When the obturator is withdrawn, the optic is inserted, the walerchamber closed and the electric: ables ale connecteal.

The form of the instruments is sucll that their insertion and handling for ordinaly (ases cause no pain, and all operations can be done with loral anesthesia. Bloeding does not often occur. Infection is reduced to a ninimum by the continuous iprigation wilh horie areil solution. The normal anterior urethra by physiologic dilatation is like a mniform tube. much like the immer. walls of the arteries; complete and jucomplete pings cau be seen, and the uniformity of the mucons membrane is interrupted only by shallow pippillate and indentures. which are sharp-cut, round openings, and when infeeted become enlarged and deeper and oflen appear diverticulir. The mucous fibers are often firmly attached to the mucous membrane and annot be dislodged by a strong stream of water in chronically infected urethias.

It is interesting to observe how man is able to open voluntarily the month of the harlder as soon as he chooses to empty the bladder. This method no doubt will be much used to cliagnos catses of noturnal enuresis, as direct olservation of the ate of urination can be secured.

By changes in the prostute many disturbances of urination take place, especially in cases of enlargement a distortion of the middle jobe. Coldselmidt. siys: "We often find that the splunctor does not rlose, but iregularly cleaves." Whether the posterior urethra acts as a reservoir in the act of mination was much discussed some years ago. If the mouth of the bladder closes completely, which as a rule can readily be seen by the aid of the instrument, it becomes easy to decide wheihar the sphincter is properly f'unctionating. Many and varied causes of disturbances of mrimation and diffienlties in the prostatic urethra can be amalyzed by direct observation of urination.

In cases of enlargement of the so-nalled midalle lobe, and the lengthening of that portion of the urethria between the colliculus seminalis and the entrance to the bladder one can see, when the patient minates, how this middle lobe is pushed forwarl and the lower wall of the prostatic urethra is pressed against the npper wall and, instead of a relaxation, a contruction of the unethria takes place. The lateral walls of the urethra lecome changed from old infectious processes, and in comparison with a normal urethra appear gramulated, liaril and inelastic. In the prostatic uredina are fomd many nucous accessories and polypoil tults.

One of the grentest points of interest is the observintion of the colliculus seminalis. Secretion from the ejaculatory ducts and prostatic ducts can be olserved whether it is spontaneously evolved or artificially prociuced through massage by jectum. All the irregularities of the mucous membraice are rearly presented; small polypoid tumors are seen plainly, not unlike the tumors of. the bladder as seen witli the ristoscope.

Goldsclmidt says: "After some time and many experiments I felt the need of modifying my instruments so that they could also be used at the same time for different operations within the urethra." With his instruments designed for operating, pathologic growths, polypoid tumors, granulations, etc., can be removed from the urethra. The greatest advantages are the distinctness with which the hypertrophied Jobes of the prostate are seen, and the heretofore unknown precision with
Filich they may be attacked. When the instrument is rotated round its axis the lateral walls, as well as the superior wall, can be seen. If the instrument is introcluced deep into the posterior urethra the urethra can be seen more clearly.

II the light is just passed into the bladder the internal nphincter can be seen, and by moving the instrument ane can appreciate the thickness of the lips of this orifice; any irregularity or thickening of the edge can also be observed very distinctly. The difference is particularly remarkable in eases of hypertrophy of the micldle lobe of the prostate. 'The larger the lobe the more one is obliged to push the instrument inward until the protuberance of the sloping part of the blader is reathed. As the window of the urethroscope is divided irito hall centimeters, one can ascertain the size of the ephincter's edge, which normally does not exceed (1.)

In hypertrophy of the prostate we find that the shape of the urethra is completely modified; the vertical diameter and length are considerably increased. We find often with the endoscope in cases of hypertrophy that a transverse fold which Goldschmidt has designated the "prostatic fold," presents before the lateral lobes. Beyond this lold lies a ravity; similar in shape to the buils, at the bottom of which is the verumontanum; in prostatic: hypertrophy it is usually atrophied.

According to the degree of hypertrophy, the lateral lobes appear like tonsils in the visual field. They are cenerally moderately developed at the external os, and endually increase in size as the center of the prostatic region is approached. Often the lateral lobes meet and press against each other. 'They generally recede toward the bladder at the extreme end of the urethra, and instend of the normal soft and regular ridge, a thick and lind lold forms the inferior edge of the bladder neck; instend of being slightly concave, as is normal, the os is generally rectilineal or oblique, indicating a thickening if either the mouth of the bladder or the extremity of tho: mildle lobe.

'The neck of the bladder having lost all elasticity, crery effort at evacuation of the urine is followed by convulsive movements of the prostatic and posterior wrethra. These movements also accompany the passage (if the contents of the bladder into the posterior urethra. 'The cletr water used for irrigation becomes turbid, being mixed with the contents of the bladder by these movements of the mrethra.

If. slight bleeding occurs the hemorrhage is washed away by the water which constantly flows through the visual ficld. The prostate presents in the field, and not only the anterior portion, but also the prostate is seen in its entirety, as the tonsils are scen in the throat.

When the nipple-like protuberances which obstruet the evacuation of urine are seen, they can be incised directly where they oppose micturition.

some time ago a method was devised of introducing an electrolytic or galvanocautery needle through the retum jnto the hypertrophied prostate; the size of the jorostate was sometimes reduced by this means. The dangers of this method and the fact that the portion obstructing urination could not be located definitely must be apparent to all.

Sellorist attempted electrolysis of the hypertrophied lobes of the prostate with Oberlaender's endoscope, but was not very successful.

lijectrolysis through the Goldschmidt urethroscope (an be practiced if desired. Goldschmidt states that the iecreuse of the congestion of the mucous membrane after 
this slight operation is marked; sometimes after the first treatment the number of nocturnal evacuations is notably decreased, and catheterization and micturition become much easier; after a few treatments more vigorous measures with the galvanocautery can be undertaken. By ignipuncture greater shrinkage can be obtained than by electrolysis, often with complete or almost complete retention; besides the enlargement of the lateral lobes, there often exists a rigidity of the vesical neck, produced by a true "middle lobe" or by a slight infiltration, which prevents the functionating of the sphincter.

The operation of Bottini and Freudenberg's modification thereof were performed in complete darkness, and are not to be compared with the Goldschmidt method, by which a full view can be obtained. The diagnosis, cven by cystoscopy, shows only the prostatic prominences in the bladder, while most of the protuberances which prevent the evacuation of urine are caused by projections of the prostatic gland into the prostatic urethra.

It is unnecessary for me to say that the Goldschrnidt method is not intended to replace prostatectomy in any way, but I trust that prostatotomy may decrease the number of cases which are now in the field of prostatectomy. Goldschmidt has used the method extensively in cases of beginning enlargement of the gland.

If one out of every five cases is malignant, possibly because of the increased irritation of the urine on a hypertrophicd gland and the increased tension and pressure, the hypertrophy in the beginning may have been benign; may not this method in the beginning of the disease offer some hope by relieving the increased tension and pressure on the middle part of the gland and by decreasing the amount of the residual urine? In any cvent, the dangers of delay are reduced to a minimum in those cases in which cancerous development is inevitable, and, in the hands of those familiar with the urethroscopic (Goldschmidt) aspects of the enlargements, are not to be considered a serious drawback to prostatotomy'. 'The prostatic urethra is sometimes thickened, according to Goldschmidt, in beginning cancerous enlargement of the gland. If this procedure might prevent cancerous development in only a very small number of cases, its use would be a valuable adjunct to urologists.

It seems almost superfluous for me again to call attention to the fact that this procedure must be used only in selected cases under the most rigid and careful nscpsis; in cases in which tolerance to instrumentation has not been established the same painstaling methods must be used as are used in cystoscopy or any other bladder or urethral instrumentation. Jisappointments will be less frequent and better results will be obtained by rigorous attention to these details and by thorough mastery of the technic and use of the instruments under ciscussion.

Tandler and Zuckerkandl agree that hypertrophy of the prostate always begins in the middle lobe, and that the mechanism of the bladder closure and the emptying of the urine may be ascribed to the sphincters of the prostate. Wilson and McGrath also agree in these findings.

Louis E. Schmidt, before the Chicago Medical Society in Narch, 1910, said :

Ocousionally it is desirable to axumine the posterior urethra, and this can be easily done with the Belfield or Swinburne instruments. The Goldschmidt instrument, which is a waterdilating instrument, can be used for both exumination and instrumentation of the anterior and posterior wethra, and is a unigue instrument. I have had oceasion to use it in the past few years and $I$ can recommend it, as no other instrument gives the same information regarding the posterior urethra and the internal urethral orifice. The retrograde cystoscope gives only the image of the internal urethral orifice from the bladder side, while the Goldschmidt instrument gives it from the urethral side.

\section{Pilcher in his excellent work says:}

The great objection to removing a section of a prostate by the galvanocautery knife has been the uncertainty of the procedure, the relatively high mortality and the fact that the benefit was only temporary. The cystoscope has removed the frrst of these objections, for the prostatic bar may be attacked under direct vision. The safest method is that devised by Young of Baltimore, who removes a prostatic bar by means of an endoscopic punch of his own design.

With all these different points taken into account, I now leave for serious consideration the Goldschmidt technic.

701 Madison Avenue.

\section{IMPERMEABLE STIRICTURE OF THE BULBO- MEMBRANOUS URETHRA}

(IMPERMEABLE TO THE PASSAGE OF INSTRUMEN'S) *

JOHN B. DEAVER, M.D., Sc.D., LL.D.

PHILADELPJIIA

Inpermeable stricture of the urethra is a condition so distressing and so dangerous to the afflicted patient that it well merits our interest and our best efforts.

The bulbomembranous urethra, as its name implies, is that portion of the urethra included within the bulb proper and extending backward through the triangular ligament and compressor urethre muscle as far as the apex of the prostate gland. Anteriorly it is, of course, continuous with the penile urethra. In this short stretch, on the average $11 / 2$ or 2 inches in length, are found the great majority of strictures which in their different stages and various complications yicld problems of treatment that demand the nicest judgment on the part of the surgeon in order to secure the best result for the individual patient.

Twenty years ago I had the privilege of addressing the American Medical Association on a similar subject, and I can now say that my opinjons have changed but little, except that the lines have been drawn a little finer, so that the various operations are made to fit the case in hand. Moreover, we have now a larger number of treated cases from which to draw conclusions, and it seems to me that our patients come to us in a better condition than they used to; one seldom sees to-day a picture such as that depicted by Cock, which I shall quote later, and which in my early days of surgery was not unusual. That this is somewhat due to improved methods of treating acute inflammatory urethritis I have no doubt; but I like to give greater recognition to the general practitioner, who is willing to recognize the time when his abilities are insufficient and to advise surgical intervention carly, so that we receive our patients in a better condition, both for the operation and for the attainment of satisfactory results.

Gradual dilatation, I will grant, has its benefits; but after organization has taken place it is my opinion that the knife is the safest and surest resource, as well as the

* IRend In the Symposium on Obstacles to Evacuation of the Bladier in the Section on Genito-Vrinary Isisenses of the American Irdical Association, at the Sixty-Julid Aunual Session, beld at Atlantle City, June, in12. 